\section{A Joint Venture for European Optics} Society (EOS), was officially founded on 12 March 1991 at a meeting in The Hague during the $\mathrm{ECO} 4$ conference. This was the latest in the series of annual international conferences in the optical sciences that represented the principal activity of the now defunct Joint Policy Committee of a partnership between the Optics Division of EPS, the European Federation of Applied Optics (EUROPTICA) and the International Society for Optical Engineering (SPIE).

EOS was created "to contribute to the progress of optics and related sciences and to promote their applications in Europe and worldwide". With individual, corporations and national societies as members, its activities will encompass the organization of conferences, the publication of a European journal and the establishing of relations with organizations serving common objectives. To achieve these goals, EOS is setting up agreements with a publisher and a logistics partner.

Just three days after the founding meeting, the EOS President, Dr. H. Walter of Rodenstock Optik GmbH in Germany and
A new society, the European Optical
Dr. R.A. Sprague from the SPIE headquarters in Bellingham, VA, USA, signed a joint venture agreement whose objectives are spelt out in a memorandum of understanding. It is acknowledged that a key objective of the joint venture is to develop logistical support for EOS to meet Europe's needs for a disciplined series of international conferences, seminars, exhibits, etc., starting in 1992 with one conference and possibly two topical meetings.

SPIE with 11500 members will assume the entire financial risk during the first two years and any profits of the venture, which is automatically renewed every two years unless one partner withdraws, will be divided $51 \%$ to EOS and $49 \%$ to SPIE. EOS will probably need to partly reinvest any profits in the early stages to bring its share of the venture's risk capital to the agreed $51 \%$.

SPIE will publish all the of the joint venture's proceedings and IOP Publishing in the UK is presently negotiating to produce, starting in January 1992, a new journal in two parts for the Society (with the editorial work done by an EOS office in Paris), two other European publishers of important existing journals in optics having declined

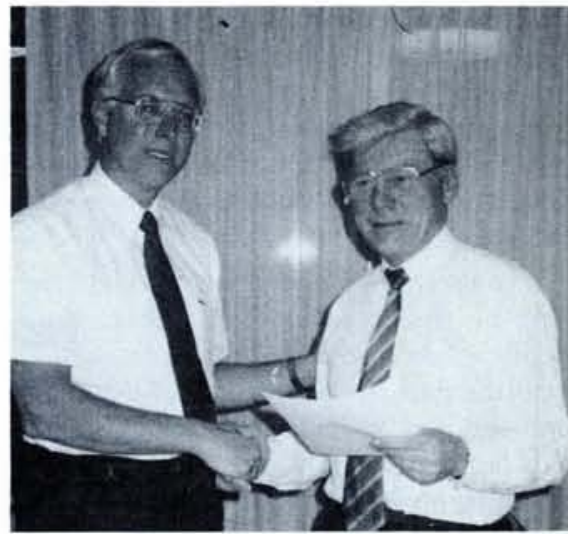

Dr. R.A. Sprague (on the left), President, SPIE, Bellingham, USA and Dr. H. Walter after signing the SPIE-EOS joint venture agreement.

to identify with a purely European, as opposed to international, operation.

With a yet-to-be-elected Board of EOS comprising a disproportionately large number of representatives of individual members ( 11 as opposed to 3 from national societies and 1 from industry), one concern is that communities in the larger countries will dominate. Control of the joint venture is vested in a seven person Board of Directors ( 3 from the EOS, 3 from SPIE and 1 appointed jointly).

Proposals for the future of the EPS Optics Division will be presented and discussed at the Council meeting in Zurich later this month. their professional activity being regulated by an organization that ensures rules of conduct, confers titles and awards diploma. However, an European Community Directive that came into force last January calls for the mutual recognition by all the EC Member States of formal professional qualifications in physics awarded by a competent authority in each State. With 1992 in mind, the aim is to allow professionals to use home-state qualifications to enter the equivalent profession in another Member State without the need to effectively repeat education and training requirements.

Under the terms of the EC Treaty, each MS must implement the necessary legislation and include a list of designated authorities for 60 or so professions.

Only the UK and Ireland have complied and the UK legislation took effect on 17 April. The Institute of Physics has been designated by the British Department of Trade and Industry as the UK authority for physics and it has an agreement to handle Ireland. Arrangements fall within the already established and uniquely British scheme for the Chartered Physicist where the designation C. Phys. guarantees competence in terms of education, experience and professional qualifications. For professional recognition under the EC Directive, a paidup individual member of the IOP must submit to the IOP together with an application:

- supporting evidence of nationality and educational awards issued by an appropriate authority:

- a recognized Diploma issued by a "competent authority" within the applicant's MS confirming additional professional training, compliance with the qualifications required for a physicist in the home country and completion of a post-secondary course in physics.

The UK Government has called upon other EC countries to "honour their Community agreements", but in the case of physics it is by no means clear how this will be done. The IOP's specific problems in implementing the UK machinery were discussed at the EPS Executive Committee meeting in March (e.g., who are the competent authorities outside the UK?). An EPS Working Group chaired by Professor van der Leun has been set up to examine the situation and make recommendations for an initiative on behalf of all EC countries.

Engineers, chemists and biologists have started making some moves but overall there appears to be little general awareness of the opportunities, notably among the physics community. Only parts of physics are covered by laws covering professional activity, and by the need to satisfy a regulatory authority before taking up a post. Most interest concerns improving the status of physicists in Europe (e.g. greater responsibility in the medical, aerospace and nuclear fields). Then there are transnational aspects calling for means to facilitate the transfer of qualifications (e.g. in teaching and medical physics) or to enhance the credibility of individual scientists (e.g. UK companies seeking European contracts say they would value widely recognized professional qualifications). All in all, the issues are more significant than simply being entitled to add some cryptic codes after one's name.

\section{Mathematica $^{\mathrm{TM}}$ \\ A System for Doing Mathematics by} Computer

A Wolfram Research Inc. product

$\square$ Numerics - Works with numbers of arbitrary magnitude and precision.

$\square$ Symbolics - Encyclopaedia of mathematical functions and operations used in arithmetic, algebra and analysis.

Procedural, functional and mathematical programming.

$\square$ Graphics - 2D, 3D and animated PostScript graphics.

Text processing - Fully interactive reports and textbooks.

$\square$ Runs on - MS-DOS based computers; Macintosh, Apollo, Hewlett Packard, IBM AIX/RT, MIPS, Silicon Graphics, Sony, Sun, VAX.

Now available in Europe from:

MathSoft Overseas, Inc.

POB 641, 1211 Geneva 3, Switzerland

Tel. ++41 (22) 465260

Fax $++41(22) 465939$ 